\title{
DEMOCRACIA REPRESENTATIVA: CONSIDERAÇÕES ACERCA DA REPRESENTAÇÃO POLÍTICA
}

\author{
Beatriz Ribeiro ${ }^{1}$ \\ Letícia Ribeiro $^{2}$
}

\begin{abstract}
RESUMO
O tema-problema da presente pesquisa diz respeito à relação da representação política e a democracia representativa moderna, a fim de traçar novas conjecturas para o enfrentamento da crise de representatividade observada nos parlamentos modernos. Nesse sentido, será utilizada uma abordagem de pesquisa interdisciplinar, por meio da qual, serão apresentadas as considerações trazidas pela teoria política contemporânea acerca da concepção teórica da representação política, destacando-se a redefinição desse instituto jurídico enquanto um processo. Utilizar-se-á do método dedutivo por meio da pesquisa bibliográfica, com interdisciplinaridade entre Ciência Política e Direito para efetivação da proposta em estudo.
\end{abstract}

Palavras-chave: Democracia Representativa; Representação Política; Teoria Política Contemporânea; Crise de Representatividade; Interdisciplinaridade.

\section{REPRESENTATIVE DEMOCRACY: THOUGHTS ABOUT THE POLITICAL REPRESENTATION}

\begin{abstract}
ABSTRAC
The central question examined by this search concerns about the relation between representation and the modern representative democracy to bring new conjectures for the representative crisis problem. Thereby, it will be used an interdisciplinary approach to present the considerations of the contemporary political theory about the theoretical conception of politic representation, focusing on the representation as a process. In addition, it will be used the deductive method, trough the technique of indirect search, with interdisciplinarity among the Political and Legal Sciences to provide the support for the study.
\end{abstract}

Key-Worlds: Representative Democracy; Political Representation; Contemporary Political Theory; Representative Crises; Interdisciplinarity.

\section{INTRODUÇÃO}

\footnotetext{
${ }^{1}$ Beatriz Ribeiro, advogada e mestranda em Instituições Sociais, Direito e Democracia pelo Programa de PósGraduação Stricto Sensu da Fundação Mineira de Educação e Cultura (FUMEC), graduada em Direito pela Faculdade de Direito de Conselheiro Lafaiete. Lattes: http://lattes.cnpq.br/4918764590566626. E-mail: ribeirobiabeatriz97@gmail.com

${ }^{2}$ Letícia Ribeiro, advogada e mestranda em Instituições Sociais, Direito e Democracia pelo Programa de PósGraduação Stricto Sensu da Fundação Mineira de Educação e Cultura (FUMEC), graduada em Direito pela Faculdade de Direito de Conselheiro Lafaiete. Lattes: http://lattes.cnpq.br/7604428071744743. E-mail: leticiar12@yahoo.com.br
} 
A problemática da representação política é tema recorrente na Ciência Política. No entanto, a relação desse instituto com a democracia moderna ainda é algo que merece pesquisa e maiores aprofundamentos dado que a consequência primeira deste ato envolve a criação do ordenamento jurídico responsável por coordenar toda sociedade.

Nessa pesquisa, por conseguinte, buscou-se, justamente, debruçar-se sobre essa relação que além de autorizar a criação e a regência legal da sociedade também constitui um grupo seleto de indivíduos responsáveis por essa atividade.

Assim, a hipótese de pesquisa considera que a compreensão da representação política enquanto um processo e uma construção pode proporcionar novas perspectivas para pensar a relação entre a sociedade e Estado a partir da constituição política. Parte-se do pressuposto de que a interdisciplinaridade entre Direito e a Ciência Política é aspecto fundamental para o avanço nas discussões sobre a constituição jurídica de uma sociedade.

Portanto, o objetivo da pesquisa foi apresentar as contribuições da teoria política contemporânea acerca do conceito teórico da representação política a fim de proporcionar nova perspectiva no enfrentamento das falhas que ocorrem na representação política; partindo da premissa de que a crise de representatividade existe.

Dessa forma, em um primeiro momento, apresentou-se a relação entre sociedade e Estado a partir de três abordagens políticas: a liberal, a republicana e a procedimentalista. Posteriormente, traçou-se considerações acerca dos fundamentos e características do regime democrático. Por fim, apresentou-se o mapa de evolução semântica do termo representação sob a perspectiva da teoria política contemporânea, utilizando-se, para tanto, das obras de Hanna Pitkin (2006), bem como da redefinição conceitual proposta por Nadia Urbinati (2006), na qual passa-se a considerar a representação política enquanto um processo e uma construção.

A conclusão proposta enfatiza como a análise etimológica do termo esclarece a relação existente entre a democracia representativa e a representação política e como a concepção teórica adotada pela teoria política contemporânea pode contribuir para o avanço no enfrentamento da problemática relativa às falhas de representação. Isso porque, referidas variáveis são os pontos que conectam o fundamento constitucional das sociedades contemporâneas: a soberania popular.

\section{ESTADO E SOCIEDADE: ABORDAGENS POLÍTICAS}


O estudo do regime democrático e da sua relação com a representação, perpassam, segundo a perspectiva da teoria política, por uma análise entre a relação da sociedade e Estado. Referida análise é objeto de estudo de diversos autores, podendo, no entanto, ser sintetizada por três abordagens da teoria política: a tradição liberal, tradição republicana e a procedimentalista.

Marcelo Cattoni (2016), a partir da metodologia dos paradigmas, ao analisar a relação entre o constitucionalismo e a democracia destaca a relação entre os conceitos de cidadão $^{3}$ e processo político. Tal pesquisa apresenta notória relevância para fins do presente estudo em relação ao regime democrático tendo em vista que através dela é possível extrair constatações acerca da relação entre Estado e sociedade nas tradições liberal, republicana e procedimentalista.

Antes de iniciar os estudos em relação a essas correntes do pensamento político moderno é importante destacar que tanto o liberalismo quanto o republicanismo compartilham a ideia de que os cidadãos são livres e iguais, pois defendem não apenas a existência de um regime democrático, mas também a constitucionalização dos direitos fundamentais (CATTONI, 2016, p. 59).

Menciona-se, desde já, que o sentido atribuído ao que seja a constituição, o regime democrático e os direitos fundamentais pelo liberalismo e republicanismo é divergente. Tal diferença pode ser constatada a partir da perspectiva e da finalidade atribuída por cada um desses pensamentos políticos à organização social e ao Estado:

\begin{abstract}
De acordo com a visão "liberal ou lockiana, o processo democrático realiza a tarefa de programar o Governo segundo o interesse da sociedade, sendo o Governo representado como um aparato de administração pública e a sociedade, como uma rede de interações entre pessoas privadas estruturada na forma do mercado. [...] $\mathrm{Na}$ visão "republicana", porém, a política vai além dessa função mediadora; ela é, sobretudo, constitutiva dos processos da sociedade como um todo. A "política" é concebida como a forma em que se reflete a vida ética real, isto é, como o meio pelo qual os membros de comunidades de certo modo solitárias se tornam conscientes de que dependem uns dos outros, e, agindo com plena capacidade de deliberação como cidadãos, modelam e desenvolvem as relações existentes de reconhecimento recíproco, transformando-as em uma associação de parceiros livres e iguais sob a vigência da lei (HABERMAS, 1995b, p. 107-108).
\end{abstract}

\footnotetext{
${ }^{3} \mathrm{O}$ conceito de cidadão utilizado pelas teorias do pensamento político moderno não é dotado da conotação crítica vislumbrada por Rosemiro Pereira Leal (1999) em seu artigo Processo Civil e Sociedade Civil. Contudo, em razão do objetivo da pesquisa, especialmente, desta seção, não será abordada a reconstrução teórica proposta pelo referido autor; salientando-se desde já ressalvas em relação ao termo "cidadão".
} 
Nesse contexto, o liberalismo lockiano (tradição liberal) vislumbra o indivíduo dotado de direitos negativos, anteriormente, a concepção de cidadão. Com efeito, os cidadãos, nesse sistema político, reafirmariam, através do sistema representativo, seus interesses privados a fim de constituir um governo que os refletissem (HABERMAS, 1995b).

Em sentido contrário, o republicanismo não considera que os fins do processo político sejam a fiscalização da atuação estatal e a proteção dos direitos determinados pela maioria. Para essa corrente do pensamento político moderno, o processo político apresenta função diferenciada, compreendendo a auto organização da sociedade, conforme se depreende da teoria de Rousseau:

Cada um de nós põe em comum sua pessoa e toda a sua autoridade, sob o supremo comando da vontade geral, e recebemos em conjunto cada membro como parte indivisível do todo. Logo, ao invés da pessoa particular de cada contratante, esse ato de associação produz um corpo moral e coletivo, composto de tantos membros quanto a assembleia de vozes, o qual recebe desse mesmo ato sua unidade, se eu comum, sua vida e sua vontade. A pessoa pública, formada assim pela união de todas as outras, tomava outrora o nome de cidade, e toma hoje o de república ou corpo político [...] (ROUSSEAU, 2002, p. 25-26).

A partir dessa compreensão do processo político os republicanos entendem que a política se volta à formação da vida ética real e ao reconhecimento de que os indivíduos dependem um dos outros. Com efeito, Habermas afirma que "com isso, a arquitetura liberal de governo e sociedade sofre uma mudança importante: além das normas hierárquicas do Estado e das regras descentralizadas do mercado, a solidariedade e a orientação para o bem comum aparecem como uma terceira fonte de integração social”, (HABERMAS, 1995b, p.108).

Tendo em vista as diferentes concepções apresentadas acerca do processo político pelas tradições liberal e republicana o cidadão, assim como a democracia em cada uma delas, também, são vistos sob óticas distintas:

Segundo a visão liberal, o status dos cidadãos é fundamentalmente determinado de acordo com os direitos negativos que eles têm em relação ao Estado e a outros cidadãos. Como portadores desses direitos, eles gozam da proteção do governo na medida em que buscam realizar seus interesses privados dentro dos limites traçados pelos estatutos legais, e isso inclui proteção contra intervenções governamentais. Direitos políticos tais como o direito ao voto e à livre expressão não têm apenas a mesma estrutura, mas também um significado semelhante enquanto direitos civis que fornecem um espaço no qual assuntos legais tornam-se livres de coerção externa. Eles dão aos cidadãos a oportunidade para afirmar seus interesses privados de tal maneira que, por meio de eleições, da composição de corpos parlamentares e da formação de um governo, esses interesses privados de tal maneira que, por meio de eleições, da composição de corpos parlamentares e da formação de um governo, esses interesses são finalmente agregados numa vontade política que provoca um impacto sobre a administração. De acordo com a visão republicana, o status dos 
cidadãos não é determinado pelo modelo das liberdades negativas que podem ser reivindicadas por esses cidadãos enquanto pessoas privadas. Direitos políticos sobretudo os de comunicação e participação políticas- são, antes, liberdades positivas. Eles garantem não a liberdade de coerção externa, mas a possibilidade de participação numa práxis comum pela qual os cidadãos podem, primeiramente, tornar-se aquilo que desejam ser: autores politicamente autônomos de uma comunidade de pessoas livres e iguais. (HABERMAS, 1995b, p. 108-109).

Assim, a conceituação do regime democrático no modelo liberal pode ser extraída da garantia ao direito de representação, mediante o voto, e da proteção aos direitos negativos dos indivíduos; podendo o processo democrático ser resumido como um jogo estratégico em que os cidadãos buscam manter ou adquirir o poder por meio da conjugação de interesses. Com efeito, no liberalismo o sistema majoritário é dotado de extrema relevância, sendo o processo político estruturado como um mercado (CATTONI, 2016).

Lado outro, a democracia no pensamento republicano não se compara a uma estrutura de mercado, ao contrário o processo democrático é centrado no diálogo e na constituição da própria sociedade.

As diferenças acima apontadas, conforme bem destacado por Marcelo Cattoni (2016) conduzem a visões distintas acerca da sociedade e sua relação com o Estado. Isto pois a visão lockiana não consagra o pacto constituinte da sociedade como um processo democrático. Por conseguinte, a partir dessa constatação tem-se que o liberalismo distingue o pacto fundamental daquele em que os cidadãos elegem seus representantes.

Assim, enquanto para o liberalismo lockiano é possível promover a dissolução do governo e a manutenção da sociedade, no republicanismo de Rousseau essa hipótese é impossível, uma vez que não há espaço para a alienação da soberania, assim como para a representatividade:

Tanto a tradição liberal quanto a republicana pressupõem uma visão de sociedade centrada no Estado. Contudo, enquanto para a primeira o Estado é o guardião de uma sociedade de mercado, para a segunda o Estado é a institucionalização autoconsciente de uma comunidade ética. De acordo com os republicanos, a formação política da vontade e da opinião da vontade e dos cidadãos cria o meio pelo qual a sociedade se constitui como uma totalidade política, onde não faz sentido distinguir-se o Estado e a sociedade (CATTONI, 2016, p. 67).

O sentido atribuído à política no regime democrático é, também, objeto de uma terceira corrente do pensamento político: a concepção procedimentalista. A partir dessa visão o processo político se afasta do idealismo republicano que torna a política dependente das virtudes dos cidadãos. Assim, muito embora prime pela formação democrática da vontade a partir da comunicação, o procedimentalismo ressalta a importância de procedimentos e das 
formas de deliberação a fim de assegurar que os argumentos, por mais diversos que sejam, integrem o processo político. Assim, "a teoria do discurso sustenta que o êxito da política deliberativa depende não da ação coletiva dos cidadãos, mas da institucionalização dos procedimentos e das condições de comunicações correspondentes" (HABERMAS, 1995b, p. 112).

Dessa maneira, constata-se que a política sob a perspectiva procedimentalista, diferentemente, da republicana percebe a pluralidade existente na sociedade. Ou seja, compreende a sociedade como um todo heterogêneo:

O surgimento do Estado-nação propiciou uma base sobre a qual pôde se articular e institucionalizar a ideia republicana de comunidade. Hoje, porém, todos vivem em sociedades pluralistas que se afastam muito da concepção de um Estado-nação fundado numa população relativamente homogênea. Diante da enorme diversidade das formas culturais de vida, dos grupos étnicos, das visões de mundo e das religiões, o Estado-nação não pode mais fornecer a base apropriada para a manutenção da cidadania democrática no futuro que se anuncia (HABERMAS, 1995a, p. 1).

Importante destacar que as diferentes conotações atribuídas à política e ao processo político nas três tradições da teoria política supramencionadas conduzem a diferentes concepções da relação entre Estado e sociedade.

Dessa maneira, enquanto para o republicanismo não há espaço para se promover uma distinção entre sociedade e Estado para o liberalismo a atuação estatal deve resguardar a estrutura de mercado definida a partir de uma seleção majoritária de interesses, conforme já destacado.

Sob a ótica procedimentalista a conceituação de democracia não precisa, necessariamente, centrar-se no Estado. É nesse contexto que essa corrente propõe que os debates possam ocorrer não somente em corpos parlamentares, mas também pelas redes informais da esfera pública:

A formação informal da opinião pública gera a "influência"; esta é transformada em
"poder comunicativo" por meio dos canais das eleições políticas; e o "poder
comunicativo é por sua vez transformado em "poder administrativo" por meio da
legislação. Como no modelo liberal, os limites entre Estado e sociedade são
respeitados, mas, neste caso, a sociedade civil fornece a base social das esferas
públicas autônomas, as quais permanecem tão distintas do sistema econômico
quanto da administração. Essa compreensão da democracia sugere um novo
equilíbrio entre as três fontes a partir das quais as sociedades modernas encontram
suas necessidades de integração: o dinheiro, o poder administrativo e a
solidariedade. As implicações normativas são óbvias: a força integradora da
"solidariedade", que não pode mais ser extraída apenas das fontes da ação
comunicativa, deveria desenvolver-se através das esferas públicas extensamente
ampliadas e diferenciadas, bem como através dos procedimentos de deliberação
democrática e de tomada de decisão juridicamente institucionalizados.
(HABERMAS, $1995 \mathrm{~b}$, p. 118). 
Apresentadas as abordagens políticas da relação entre Estado e sociedade, segue-se na descrição dos fundamentos e características do regime democrático, destacando-se três fontes da teoria política ${ }^{4}$ que explicam a conformação do modelo democrático moderno, a fim de que, posteriormente, possa ser analisada a variável da representação política, objeto da presente pesquisa.

\section{FUNDAMENTOS E CARACTERÍSTICAS DO REGIME DEMOCRÁTICO}

A democracia enquanto forma de governo, é antiga e daí decorre a dificuldade de apresentar um conceito único; isso porque, conforme elucida Robert Dahl (2012), a democracia se desenvolveu ao longo milhares de anos e se origina de várias fontes; as quais podem ser identificadas como oriunda três teorias: teoria clássica ou aristotélica, tradição medieval e a teoria Moderna, conforme explicam Norberto Bobbio, Nicola Matteucci e Gianfranco Pasquino:

Na teoria contemporânea da Democracia confluem três grandes tradições do pensamento político a) a teoria clássica, divulgada como teoria aristotélica, das três formas de Governo, segundo a qual a Democracia como Governo do povo, de todos os cidadãos ou seja, de todos aqueles que gozam dos direitos de cidadania, se distingue da monarquia, como Governo de um só, e da aristocracia como Governo de poucos; b) a teoria medieval, de origem romana, apoiada na soberania popular, na base da qual há a contraposição de uma concepção ascendente a uma concepção descendente da soberania conforme o poder supremo deriva do povo e se torna representativo ou deriva do príncipe e se transmite por delegação do superior para o inferior; c) a teoria moderna, conhecida como teoria de Maquiavel, nascida com o Estado moderno na forma das grandes monarquias segundo a qual as formas históricas de Governo são essencialmente duas: a monarquia e a República [...] (BOBBIO; MATTEUCCI; PASQUINO, 1998, p.320).

A tipologia desenvolvida por Aristóteles distingue as formas de governo entre formas puras e formas corruptas, tendo em vista um governo realizado em prol de um "interesse geral" ou no "interesse próprio". Assim, de acordo com a tipologia aristotélica, a democracia diz respeito à forma corrupta, sendo definida como "Governo de vantagem para o pobre"; contrapondo-se a noção de "Governo de vantagem para o monarca (tirano) e ao "Governo de vantagem para os ricos (oligarquia). Aristóteles, ainda, subdividiu a Democracia em cinco formas, desde aquelas em que ricos e pobres participam do Governo em condições paritárias até as formas nas quais a massa predominaria sobre a lei, sendo esta última a forma corrupta

\footnotetext{
${ }^{4}$ A concepção da teoria política, embora não forneça uma análise crítica que possibilite repensar o modelo democrático moderno, foi utilizada em razão do enfoque interdisciplinar proposto na presente pesquisa.
} 
de Governo popular a qual o filósofo se refere (BOBBIO; MATTEUCCI; PASQUINO, 1998, p.320).

A importância dessa tripartição feita por Aristóteles se revela mais pelas suas repercussões na tradição do pensamento político do que pela divisão em si, passando por algumas variações:

\begin{abstract}
Não faltaram algumas variações, entre as quais se destacam três principais: a) a distinção entre formas de Estado e formas de Governo, elaborada por Bodin, com base na distinção entre a titularidade e o exercício da soberania, com o que se pode ter uma monarquia, um Estado em que o poder soberano pertence ao rei, governado democraticamente pelo fato de as magistraturas serem atribuídas pelo rei a todos indistintamente ou uma democracia aristocrática, como foi Roma durante um certo período de sua história, ou uma aristocracia democrática, e assim por diante; b) a supressão da distinção entre formas puras e formas corruptas, feita por Hobbes, com base no princípio de que para um poder soberano absoluto não se pode estabelecer nenhum critério para distinguir o uso do abuso de poder e portanto o Governo bom do Governo mau; c) a degradação introduzida por Rousseau, das três formas de Governo nos três modos de exercício do poder executivo ficando firme o princípio de que o poder legislativo, isto é, o poder que caracteriza a soberania pertence ao povo cuja reunião num corpo político através do contrato social Rousseau chama de república não de Democracia (que é apenas uma das formas com que se pode organizar o poder executivo) (BOBBIO; MATTEUCCI; PASQUINO, 1998, p.321).
\end{abstract}

A tradição romano-medieval, por sua vez, pautava-se na teoria da soberania popular a partir de algumas passagens do Digesto segundo a qual a autoridade do príncipe foi dada pelo povo. Assim, a tradição romana inaugurou na teoria democrática a concepção de que a fonte originária do poder soberano é sempre do povo, tendo, por conseguinte, apresentado a distinção entre a titularidade e o exercício desse poder. Em específico, acerca do exercício do poder soberano as discussões romanas concentravam-se em identificar se a transferência da titularidade deveria se dar de forma definitiva, ou seja, transferindo-se tanto o exercício como a titularidade, ou se apenas tratava-se de uma concessão temporária e revogável, permanecendo a titularidade no povo, cofiando-se ao príncipe apenas o exercício (BOBBIO; MATTEUCCI; PASQUINO, 1998).

Já a tradição republicana moderna, tem sua origem identificada na obra de Maquiavel e se concentra nas reflexões acerca da República enquanto forma de Estado. Assim, muito embora a diferença entre democracia e República se sobreponham e se confundam, há que se identificar quais das formas de democracia está sendo considerada posto que a depender da mesma a forma republicana poderá coexistir com um governo não democrático:

[...] Ainda uma vez, se por Democracia se entende a forma aristotélica, a república não é Democracia; mas no seu caráter peculiar de "Governo livre", de regime antiautocrático, encerra um elemento fundamental da Democracia moderna na medida em que por Democracia se entende toda a forma de Governo oposta a toda a forma 
de despotismo. [...] Mas é sobretudo em Rousseau, grande teórico da Democracia moderna, que o ideal republicano e democrático coincide perfeitamente. No Contrato Social confluem até se fundirem, a doutrina clássica da soberania popular (BOBBIO; MATTEUCCI; PASQUINO, 1998, p.323).

Ainda no que diz respeito à democracia, há que se considerar as duas principais doutrinas políticas que se confrontaram nessa discussão: o liberalismo e o socialismo. A concepção liberal associou ao modelo de Estado Liberal (garantias de alguns direitos fundamentais) a democracia representativa. Por sua vez, a concepção socialista, considerou a democracia como um elemento integrante do modelo de Estado preconizado, posto que o reforço da base popular era uma das metas dos teóricos do socialismo (BOBBIO; MATTEUCCI; PASQUINO, 1998).

Passadas as principais correntes teóricas que debruçaram-se sobre a democracia, bem como pelas doutrinas liberais e sociais, importe mencionar acerca do conceito dessa forma de governo.

\subsection{Definição de democracia: um conceito múltiplo}

Antes de adentrar na discussão acerca do conceito de democracia, há que se mencionar que as diversas tipologias dadas aos regimes democráticos variam de acordo com o critério de classificação adotado. Assim, levando-se em conta o critério jurídico-institucional tem-se um regime presidencial ou parlamentar, concentrando-se a diferença na relação entre legislativo e executivo. Ao se considerar o critério partidário, tem-se uma subdivisão, em relação ao número de partidos, a distinção entre os regimes se dá entre sistemas bipartidários e multipartidários e com relação aos polos de atração, regimes bipolares ou multipolares, a depender da relação entre Governo e oposição (BOBBIO; MATTEUCCI; PASQUINO, 1998). Assinala-se que referidas tipologias dizem respeito a uma noção comportamental da democracia podendo nesse aspecto, diferenciar-se, ainda, democracia formal e democracia substancial:

Para evitar a confusão entre dois significados tão diversos do mesmo termo prevaleceu o uso de especificar o conceito genérico de Democracia como um atributo qualificante e, assim se chama de 'formal' a primeira e de 'substancial' a segunda. Chama-se forma à primeira porque é caracterizada pelos chamados 'comportamentos universais' (universali procedurali), mediante o emprego dos quais podem ser tomadas decisões de conteúdo diverso (como mostra a co-presença de regimes liberais e democráticos ao lado dos regimes socialistas e democráticos). Chama-se substancial à segunda porque faz referência prevalentemente a certos conteúdos inspirados em ideais característicos da tradição do pensamento 
democrático, com relevo para o igualitarismo. Segundo uma velha fórmula que considera a Democracia como Governo do povo para o povo, a democracia formal é mais um Governo do povo; a substancial é mais um Governo para o povo. (BOBBIO; MATTEUCCI; PASQUINO, 1998, p. 328).

Por meio dessa distinção depreende-se que a noção de um governo democrático envolve não apenas os procedimentos pelos quais são tomadas as decisões em uma sociedade institucionalmente organizada, mas também pela definição dos conteúdos dessas decisões; sendo, que um sentido não necessariamente engloba o outro:

[...] Para não nos perdermos em discussões inconcludentes é necessário reconhecer
que nas duas expressões 'Democracia formal' e 'Democracia substancial', o termo
Democracia tem dois significados nitidamente distintos. A primeira indica um certo
número de meios que são precisamente as regras de comportamento acima descritas
independentemente da consideração dos fins. A segunda indica um certo conjunto de
fins entre os quais sobressai o fim da igualdade jurídica, social e econômica,
independentemente dos meios adotados para os alcançar (BOBBIO; MATTEUCCI;
PASQUINO, 1998, p.323).

Apesar da ampla divulgação das noções de democracia formal e substancial tanto na Ciência Política quanto na área jurídica, a definição do significado de democracia é tarefa difícil e conforme indicado no início do terceiro capítulo, isso se deve ao fato de que a democracia se desenvolveu ao longo de milhares de anos e se origina de várias fontes. Além disso os problemas que decorrem das teorias democráticas são numerosos e podem aparentar não ter solução (DAHL,2012).

As confusões também estão relacionadas, ao fato de que o termo "democracia" pode ser utilizado para designação de um ideal ou de regimes de governo e, ainda, para definir se determinada forma de governo adotada é ou não democrática.

Ainda de acordo com o referido cientista político, a democracia enquanto uma entidade do 'mundo real' pode ser percebida como um conjunto distinto de instituições e práticas políticas; um corpo particular de direitos, uma ordem socioeconômica, um sistema que garante certos resultados vantajosos ou um processo sem igual para a tomada de decisões coletivas e vinculativas (DAHL, 2012).

Conforme recorda André Del Negri (2008), a definição da democracia é muitas vezes relacionada à retórica "governo do povo, pelo povo e para o povo". Contudo, conforme se sugere, o conceito de democracia é muito mais amplo, não podendo ser resumido, pela conexão democracia-voto-cidadania. 
Dessa forma, segue-se à apresentação das contribuições da teoria política contemporânea abaixo elencadas, as quais, considera-se como relevantes para reflexão do tema-problema.

\section{A REPRESENTAÇÃO POLÍTICA E A DEMOCRACIA MODERNA}

A representação política encontra-se estritamente relacionada à democracia moderna, eis que referido instituto surgiu como uma alternativa ao exercício do regime democrático nos Estados Modernos. Assim, a representação pode ser entendida enquanto prática política ou sob a perspectiva de seu conceito teórico; enquanto prática as considerações sobre ela dizem respeito ao seu impacto na conformação da dinâmica política dos Estados Modernos e pode ser abordada sob uma perspectiva histórica ${ }^{5}$. Já o conceito teórico, ou seja, as origens semânticas, e sua estruturação no âmbito das ideias implica uma perspectiva analítica e envolve uma digressão da obra de autores clássicos da teoria política (SILVA, 2013).

\subsection{Representação política: mapa semântico do conceito teórico}

As considerações acerca do conceito teórico da representação, podem ser traçadas por meio de uma análise acerca das mutações semântica do termo. Tal exercício analítico se justifica, pois a relação entre as palavras e o mundo é complexa, na medida em que no campo dos fenômenos sociais, culturais e políticos, as palavras são constituídas pelas condutas humanas; como bem resumiu Wittgenstein: "o mundo e as palavras mudam juntos". (WITTGENSTEIN, 1968, s.p.). Assim, considerando-se a representação enquanto em fenômeno humano - cultural, político, jurídico, social - é possível traçar seu mapa semântico:

[...] O mapa semântico das palavras inglesas da família 'represent' não corresponde bem ao 'mapa semântico' de termos cognatos até mesmo em outros idiomas muito próximos ao inglês. Por exemplo, a língua alemã tem três palavras - vertreten, darstellen e repräsentieren- que geralmente são traduzidas pela palavra inglesa "represent". Darstellen significa "retratar" ou "colocar algo no lugar de"; vertreten significa "atuar como um agente para alguém". O significado de repräsentieren é próximo ao de vertreten, mas é mais formal e possui conotações mais elevadas (teóricos alemães da política, às vezes, argumentam que meros interesses privados egoístas podem ser vertreten, mas o bem comum ou o bem do Estado devem ser repräsentiert). Entretanto, o significado de repräsentieren não é, de forma alguma, próximo àquele de darstellen. Então, para quem fala em inglês o modo pelo qual uma pintura, um pintor ou um ator de palco representam, e o modo pelo qual

\footnotetext{
${ }^{5}$ Em razão dos objetivos da pesquisa, a perspectiva histórica não será objeto de aprofundamento.
} 
um agente ou um legislador eleito representam, obviamente, estão ligados ao mesmo conceito. $O$ mesmo não acontece para quem fala em alemão (PITKIN, 2006, p.16, grifo nosso).

Conforme explicita Hanna Pittkin (2006), a origem do termo representação é latina, muito embora, em seu significado original não tivesse relacionado com governo ou outras instituições:

\begin{abstract}
A palavra latina repraesentare significa 'tornar presente ou manifesto; ou apresentar novamente', e, no latim clássico, seu uso é quase inteiramente reservado para objetos inanimados. Pode significar torná-los literalmente presentes, trazê-los à presença de alguém. Também pode significar apresentar-se à corte em resposta a uma convocação; literalmente, tornar-se presente. Pode significar também tornar presente uma abstração em um objeto, ou por meio dele, como ocorre quando uma virtude parece encarnada na imagem de certo rosto. E pode significar substituição de um objeto por outro - em vez do outro - ou, a antecipação de um evento, trazendo-o para o presente. Pode significar 'desempenhar imediatamente' e mesmo 'pagar em dinheiro'. Não tem a menor relação com pessoas representando outras pessoas, ou com o Estado Romano (PITKIN, 2006, p.17).
\end{abstract}

Assim, verifica-se que o mapa semântico do termo representação em algum momento relacionou-se a noção de governo e instituições, pelo que a utilização do termo (perspectiva analítica) e seu impacto na conformação da dinâmica política (perspectiva histórica) em algum momento se fundem.

Ademais, tem-se que a noção de representação enquanto uma relação indivíduoindivíduo ou indivíduo-coletivo, tem em seu embrião a utilização na Idade Média pela literatura cristã, como um tipo de encarnação mística, na qual a figura do Papa e dos Cardeais são tidos como 'representantes' de Cristo e dos apóstolos no século XIII - muito embora essa utilização semântica não tenha conteúdo de delegação ou agência. Nesse mesmo período histórico, os juristas medievais utilizavam o termo no sentido de uma 'personificação da vida coletiva' - o conjunto de homens, a comunidade, deveria ser vista como uma pessoa - embora efetivamente não o fosse. Nesse aspecto, cumpre esclarecer, que muito embora os glosadores romanos e, posteriormente, os canonistas, possuíssem uma ideia de que o príncipe ou o imperador atuassem pelo povo, não utilizavam a palavra 'representação' (PITKIN, 2006).

Segundo Hanna Pitkin (2006) essa mudança semântica do termo representação da utilização para designar coisa para a designação de indivíduos também teria ocorrido na língua francesa e na língua inglesa:

Um desenvolvimento semelhante parece ter ocorrido no francês. Pelo menos de acordo com o Littré, a palavra représenter era usada para imagens e objetos inanimados que encarnam abstrações, muito antes de vir a significar algo como uma pessoa agindo por outras. Mas, no século XIII, pode-se falar de um encarregado representando a pessoa de seu senhor. A mesma seqüência de desenvolvimento 
também ocorre na língua inglesa, depois do aparecimento da palavra 'represent', provavelmente no final do séc. XIV. Naquele ponto, de acordo com o Oxford English Dicitionary, a palavra significa "trazer própria pessoa, ou outra pessoa, à presença de alguém"; "simbolizar ou encarnar concretamente"; "trazer à mente" [...] (PITKIN, 2006, p. 22-23).

A relação entre o decurso dos acontecimentos históricos e as mudanças semânticas que foram ocorrendo na utilização do termo 'representação' são demostradas por Hanna Pitkin (2006) no surgimento e evolução do parlamento inglês, que inicialmente dizia respeito a uma relação meramente administrativa entre cavaleiros, burgueses e o rei, para então, se ampliar para a ideia de representação política:

Para compreender como o conceito de representação entrou no campo da agência e da atividade política, deve-se ter em mente o desenvolvimento histórico de instituições, o desenvolvimento correspondente no pensamento interpretativo sobre aquelas instituições e o desenvolvimento etimológico dessa família de palavras. [...] O desenvolvimento da teoria política, de interpretações a respeito do que o Parlamento estava fazendo, acompanhou os desenvolvimentos que ocorriam na realidade. Inicialmente, os cavaleiros e os burgueses eram vistos como os servidores, ou delegados, ou procuradores de suas comunidades. Eles não eram chamados de representantes porque a palavra ainda não tinha aquele significado. No século XV, à medida que os Comuns passaram a atuar como um corpo unificado, os membros do Parlamento ocasionalmente eram mencionados como, em conjunto, "procuradores e delegados de todos os condados [...] e de todas as pessoas do país". Eles começaram a se ver, e a serem vistos, como aqueles que "vinham pela comunidade do lugar" ("were comem for the communalte of the Londe"). [...] A elaboração adicional de que cada membro do Parlamento atua para a nação como um todo veio ainda mais tarde. [...] Essas visões em mudança sobre a função dos membros do Parlamento ligaram-se a duas outras tradições de pensamento: a idéia de que todos os homens estão presentes no Parlamento, e a idéia de que o governante simboliza ou encarna o país como um todo. [...] A palavra latina repraesentare passa gradualmente a ser utilizada em conexão com esse conjunto de idéias. Então, à medida que a autoridade do Parlamento cresce, e seu papel em declarar a lei é reconhecido mais amplamente, essa posição simbólica é atribuída conjuntamente ao Rei-no-Parlamento, como um corpo ou corporação únicos. [...] A evidência etimológica não é inteiramente clara, mas sugere que toda a família de termos parece ter sido aplicada primeiramente ao Parlamento como um todo, ou aos Comuns como um grupo. [...] Os termos parecem ser utilizados, primeiramente, como uma expressão de - e como uma demanda por - autoridade, poder e prestígio. [...] A mais antiga aplicação que conheço do substantivo "representante" a um membro do Parlamento ocorre em 1651, quando Isaac Pennington, o Jovem, escreve: "O direito fundamental, segurança e liberdade do Povo; que radica no próprio Povo, e de forma derivada no Parlamento, nos substitutos ou nos representantes do povo". [...] Mas em 1651 também é o ano em que Hobbes publicou o Leviathan, o primeiro exame da idéia de representação na teoria política. [...] No Leviathan, Hobbes define a representação em termos dos aspectos formais da agência legal, especialmente em termos de autorização: um representante é alguém que recebe autoridade para agir por outro, quem fica então vinculado pela ação do representante como se tivesse sido a sua própria. (PITKIN, 2006, p.21-28, grifo nosso). 
Portanto, verifica-se que o desenvolvimento etimológico do termo 'representação' em seu aspecto político havia se estabelecido antes do final do século XVII; continuando, no entanto, a ser elaborado e utilizado na teoria política nos séculos XVII e XIX (PITKIN, 2006).

Esse desenvolvimento etimológico na teoria política também está, intimamente, relacionado aos debates teóricos relacionados ao paradoxo ${ }^{6}$ inerente ao próprio significado da representação (tornar presente o ausente) e a relação entre a representação e a democracia (PITKIN, 2006):

[...] Na teoria política, o paradoxo é recoberto por várias preocupações substantivas: a relação entre os representantes na legislatura, o papel dos partidos políticos, a medida em que os interesses locais e parciais se encaixam no bem nacional, a forma pela qual a deliberação se relaciona com o voto e ambas se relacionam com o exercício do governo etc. (PITKIN, 2006, p.30).

A representação, na teoria política foi sendo incorporada à ideia de República, na medida em que foi associada à ideia de que tornaria possível a democracia - isso, principalmente na América:

Alexander Hamilton, John Jay e James Madison, nos Artigos Federalistas, apresentam o governo representativo como um dispositivo adotado no lugar da democracia direta, porque seria impossível reunir um grande número de pessoas em um único lugar. A representação é assim um "substituto para o encontro pessoal dos cidadãos” (PITKIN, 2006, p.35).

As discussões teóricas acerca da relação entre representantes versus representados ou, ainda, entre interesses do representante versus interesse dos representados, ou seja, representação de interesses versus representação de pessoas, são tratadas por diversas correntes teóricas no campo da ciência política ${ }^{7}$, não sendo objetivo do presente a elucidação pormenorizada das mesmas.

Por fim, menciona-se que a utilização do termo representação pela teoria política, deve estar associado à noção que se dá à política, como muito bem destacou Hanna Pitkin (2006):

Enquanto a política é igualada ao governo e o governo é visto como um meio para a realização de fins privados e parra a conciliação de reivindicações privadas conflitantes numa forma geral aceitável, as instituições representativas corretamente

\footnotetext{
${ }^{6}$ Hanna Pitkin delimita esse paradoxo como a polêmica sobre o mandato e a independência (PITKIN, 2006).

${ }^{7} \mathrm{Na}$ doutrina do liberalismo político, mormente na abordagem utilitarista, apesar do enfoque nos interesses individuais, reconhece-se a existência de algo que se aproxima de um interesse público objetivo, que deve de alguma maneira incluir e abarcar os interesses individuais - vide nesse sentido John Stuart Mill (1947), Jeremy Bentham (1843). Rousseau, apesar de não argumentar no sentido de interesse, também comunga dessa lógica, defendendo a existência de uma vontade geral (1974) - segundo ele é possível que uma pessoa tenha vontade no lugar de outras, mas não há garantia de que essa vontade coincida com as vontades dos outros. Cumpre destacar que Rousseau era cético em relação à ideia de representação na função legislativa; segundo ele "o Povo, em sua função legislativa não pode ser representado). (PITKIN, 2006).
} 
elaboradas podem servir muito bem a esses propósitos. Mas se sua função real é a de dirigir nossa vida pública compartilhada e se seu valor real reside na oportunidade de dividir poder e responsabilidade sobre naquilo que estamos fazendo conjuntamente como sociedade, então ninguém mais pode fazer minha política "por" mim e a representação pode significar apenas, na maior parte das vezes, a exclusão da maioria das pessoas dos benefícios da política (PITKIN, 2006, p. 42).

Nesse particular, segue-se as considerações traçadas por Nardia Urbinati (2006) sobre a representação enquanto um processo.

\subsection{Representação política como processo: o conceito da teoria política contemporânea}

Após as considerações traçadas acerca das mudanças semânticas do termo representação e como essas mudanças foram influenciadas e influenciaram na dinâmica da conformação da democracia representativa moderna, é relevante mencionar as reformulações desse conceito na teoria política contemporânea, que passam a incorporar o papel da sociedade civil ${ }^{8}$ enquanto um representante político.

Nesse sentido, a representação passa a ser vista como um processo e como uma construção (URBINATI, 2006). Essa redefinição do conceito teórico adotado pela teoria política contemporânea ${ }^{9}$ está relacionada às formas de exercer a representação nas sociedades contemporâneas: "representar envolve distintos atores e arenas do Estado e da sociedade, os quais precisam manter interação contínua com os representados. Nesse sentido, é um fenômeno ao mesmo tempo societal e institucional" (ALMEIDA, 2014, p.176).

Conforme esclarece Débora Rezende de Almeida (2014) a redefinição do conceito de representação apresentada, principalmente nas obras de Nádia Urbinati e Pierre Rosanvallon $^{10}$, mostram-se fundamentais para a compreensão da pluralidade da representação na contemporaneidade, pois apesar de ser um conceito há muito discutido na literatura política, a representação geralmente esteve associada às tendências pluralistas e

\footnotetext{
${ }^{8}$ Menciona-se que o termo sociedade civil foi empregado em razão da reprodução da teoria contemporânea moderna de Nadia Urbinati (2006); no entanto, conforme, anteriormente, salientado, o emprego deste termo pelos doutrinadores do direito é visto com ressalvas em razão da crítica apontada por Rosemiro Pereira Leal (1999).

${ }^{9}$ De acordo com Débora Rezende de Almeida: “A contribuição da teoria democrática contemporânea vai na direção de pensar outros modos de ação em que o representante mereça ser chamado de representativo e, portanto, recupera o aspecto contínuo e plural do conceito, no qual é difícil estabelecer uma unidade" (ALEMIDA, 2014, p.182).

${ }^{10}$ Muito embora o referido autor também compartilhe da redefinição de representação enquanto processo, não serão objeto do presente as considerações acerca de sua teoria visto que o enfoque teórico por ele adotado aproxima-se da teoria social (ALMEIDA, 2014).
} 
institucionalistas, que reduziam o debate ao tema do governo representativo e à lógica da representação nas esferas do Estado. (ALMEIDA, 2014, p.177).

De forma geral referida autora destaca que dentre as contribuições da redefinição do conceito de representação proposta por Nadia Urbinati (2006) tem-se a crítica à noção de soberania enquanto alienação de direito e ato único da vontade; isso porque, depreende-se da redefinição proposta que a eleição não diz respeito a um ato de transferência da soberania, mas uma vontade expressa em um determinado momento, sendo, portanto, a legitimidade da democracia representativa garantida não apenas por eleições livres e regulares, mas também da ativação de uma comunicatividade corrente entre a sociedade civil e política. Isso decorre, justamente, da proposição de Urbinati de se considerar a representação como um instituto de natureza intrinsecamente dual que subentende tanto a ação de um agente autorizado quanto à noção de que foi criado uma unidade que antes não existia (ALMEIDA,2014, p.178).

Para Nadia Urbinati (2006) a democracia moderna pode ser definida como um governo de discussões no qual a opinião pública e a votação de representantes são as únicas formas diretas de direito dos cidadãos. De acordo com a autora é paradoxal definir esse governo como democrático, pois o único momento em que os cidadãos decidem diretamente é quando delegam o poder legislativo. Assim, para a autora as eleições significam que a soberania popular aparece apenas em intervalos raros e fixos; a função das eleições não é tornar a democracia mais democrática, mas torná-la possível. Uma vez que admitimos que precisamos de eleições, minimizamos a democracia por reconhecermos que o sistema não pode ser operado pelo povo por si mesmo ${ }^{11}$ (URBINATI, 2006, p. 3, tradução nossa).

O principal argumento de Nadia Urbinati (2006) é de que a democracia e a representação são complementares e buscam, analisar em quais condições a representação é democrática; ou seja, o modo pelo qual a participação política pode ativar variadas formas de controle e autorização dos cidadãos. Em suma, para a autora, a representação política é mais do que um sistema de divisão do trabalho e uma instituição do Estado; a representação

\footnotetext{
${ }^{11}$ No original: "Properly speaking, modern democracy is a "government by discussion" in which public speaking and voting for representatives (rarely on issues) are the only direct formal rights adult citizens are Always entitled to. Is paradoxical to call it democratic, for the only moment the citizens decide directly is when they delegate legislative power. Elections mean that popular sovereignty appears only "at fixed and rare intervals [...] Their function is "not to make a democracy more democratic but to make democracy possible. Once we admit the need for elections, we minimize democracy for we realize that the system cannot be operated by the demos itself" (URBINATI, 2006, p.3).
} 
política implica em um complexo processo político que ativa a soberania popular além do ato formal de autorização eleitoral ${ }^{12}$ (URBINATI, 2006, p. 4-5, tradução nossa).

A concepção do governo democrático moderno como sendo aquele definido pela relação entre participação e representação e não apenas eleições, é a questão central para a compreensão da redefinição proposta. Assim, a questão crucial da representação é a relação entre o interior das instituições estatais e o exterior criado pelas eleições ${ }^{13}$ (URBINATI, 2006, p. 8, tradução nossa). Isso significa que, a representação política pode ser uma forma de articulação da relação entre Sociedade e Estado.

Compartilhando dessa concepção ampliada do processo político democrático, André Del Negri (2008), afirma que o voto deve ser visto como uma parcela mínima da democracia, uma vez que o povo não se inclui no sistema somente pelos direitos políticos, mas pelo cumprimento de outros direitos fundamentais, que envolvem também a reivindicação e a fiscalização (DEL NEGRI, 2008, p. 77).

Acerca da existência da crise de representatividade, bem como, da urgência do enfrentamento da mesma, André Del Negri, citando entrevista televisiva concedida por Rosemiro Pereira Leal destaca que:

[...] A Democracia é um sistema exercitado pelos cidadãos (destinatários do direito) os quais, não podem ser infantilizados por um Estado maternal (doação de direito/assistencialismo), como se fossem apenas consumidores, e não gestoresfiscalizadores do direito. De todo modo, quando se diz que a sociedade não está praticando Democracia, o que está havendo, é uma confissão de omissão dos operacionalizadores do sistema (cidadãos e instituições), na execução da Constituição (projeto democrático) (LEAL, lido em DEL NEGRI, 2008, p.78).

Muito embora, os avanços de Nadia Urbanitatti (2006) fiquem restritos a uma noção de julgamento político, a redefinição por ela proposta mostra-se essencial para os aprofundamentos dos estudos relativos à efetivação da soberania popular no contexto do Estado Democrático de Direito.

\footnotetext{
${ }^{12}$ No original: "This book explores (and defends) the arguments of the minority that believes democracy and representation are complementary rather than antithetical. [...] My goal is to inquire into the conditions under which representation is democratic - that is, a mode of political participation thar can activate a variety forms of citizen control and oversight. [...] In sum, political representation is far more than a system of Division of labor and a state institution; it entails a complex political process that activates the "sovereign people" well beyond the formal act of electoral authorization" (URBINATI, 2006, p.4-5).

${ }^{13}$ No original: "The government of the moderns is not defined by election per se, but by the relationship between participation and representation (society and the state) instituted by elections. [...] The crucial factor of representation is the relationship between the inside of state institutions and the outside created by elections" (URBINATI, 2006, p.8).
} 


\section{CONCLUSÃO}

Por meio da pesquisa proposta, buscou-se enfatizar como a consideração do mapa semântico do termo "representação", sob uma perspectiva etimológica, pode contribuir para a compreensão da relação entre democracia representativa e a representação política, mormente, no aspecto que diz respeito à constituição do Estado pela sociedade e vice-versa.

Nesse sentido, a redefinição do termo representação política apresentada pela teoria política contemporânea, segundo a qual, a representação política, possui um caráter dual (processo e construção), corrobora a conjectura de que a efetivação da soberania popular e a construção do Estado Democrático de Direito, perpassam por essa análise, visto que se retorna ao papel participativo dos indivíduos na constituição do Estado, os quais deixam de ser vistos como mero espectadores chamados em momentos específicos para autorizar todos os atos que se seguem ao processo eletivo.

\section{REFERÊNCIAS BIBLIOGRÁFICAS}

ALMEIDA, Débora Rezende de. Representação como processo: a relação Estado/sociedade na teoria política contemporânea. Revista de Sociologia e Política. v.22, n. 50, p.175-199, jun. 2014.

BOBBIO, Norberto; GIANFRANCO, Pasquino; MATTEUCCI, Nicola. Dicionário de política. Trad. Carmen C, Varriale et al. Coord. Trad. João Ferreria. 11 ed. Brasília: Editora Universidade de Brasília, 1998.

DAHL, Robert. A democracia e seus críticos. Trad. Patrícia de Freitas Ribeiro. São Paulo: WMF Martins Fontes, 2012.

DEL NEGRI, André. Controle de constitucionalidade no Processo Legislativo: teoria da legitimidade democrática. 2 ed. Belo Horizonte: Fórum, 2008.

HABERMAS, Jürgen. O Estado-Nação europeu frente os desafios da globalização: o passado e o futuro da soberania e da cidadania. Trad. Antônio Sérgio Rocha. Revista Novos Estudos. São Paulo: Cebrap, n. 43, nov. 1995a.

HABERMAS, Jürgen. Três modelos normativos de democracia. Trad. Leonardo Avritzer. Caderno Escola do Legislativo. Belo Horizonte, n. 3, p. 105-122, jan.-jun., 1995b. 
LEAL Rosemiro Pereira. Processo Civil e Sociedade Civil. In PACHECO, José da Silva. Evolução do Processo Civil Brasileiro. Editora Renovar, 2 ed., p.7-20. Rio de Janeiro, 1999.

OLIVEIRA, Marcelo Andrade Cattoni de. Devido processo legislativo: uma justificação democrática do controle jurisdicional de constitucionalidade das leis e do processo legislativo. 3, ed. Belo Horizonte: Fórum, 2016.

PITKIN, Hanna Fenichel. Representação: palavras, instituições e idéias. Trad. Wagner Pralon Mancuso; Pablo Ortellado. No original: Representation - Political innovation and conceptual change, Cambridge University Press, 1989. Lua Nova, São Paulo, n.67, p.15-47, 2006.

ROUSSEAU, Jean-Jacques. Do contrato social. Trad. Ronaldo Roque da Silva. Disponível em: http://www.ebooksbrasil.org/adobeebook/contratosocial.pdf. Acesso em: 27 set. 2020.

SILVA, Eduardo Moreira da. As ressignificações da representação e da legitimidade política: um estudo sobre representantes no CEDCA-MG. Programa de Pós-Graduação em Ciência Política. Universidade Federal de Minas Gerais: Belo Horizonte, 2013.

URBINATI, Nadia. Representative democracy: principles and genealogy. The University of Chicago Press, 2006.

WITTGENSTEIN, Ludwig. 1968. Philosophical Investigations. Traduzido por G.E.M. Anscombe, 3, ed. New York: Macmillan. 